\title{
Juan Pablo Piñeiro. Cuando Sara Chura despierte.
}

216 páginas. La Paz, La Paz: OFFAVIM, 2003. (En la contratapa, comentario de Jesús Urzagasti).

La novela Cuando Sara Chura despierte del joven escritor Juan Pablo Piñeiro (La Paz 1979) re-entrama el entrecruce de lo andino con lo occidental en el momento contemporáneo, desde la remisión a la Entrada del Gran Poder el "13 de junio de 2003". Según varios estudios, esta fiesta se inicia en la ciudad de La Paz en 1920, para rendir adoración a un lienzo del siglo XVII que representa el misterio de la Santísima Trinidad o Gran Poder "único Cristo de tres rostros", al decir de la novela. En su ficcionalización, Piñeiro tuerce la orientación católico-cristiana de la fiesta inventando una entidad marcadamente aymara - Sara Churacapaz de encarnar lo sagrado y el misterio, ya no de las tres personas del Dios católico (el Padre, el Hijo y el Espíritu Santo), sino desde múltiples "pieles" y corporizada en una de ellas como la bailarina "la lechera" de la comparsa de los waka-wakas. ${ }^{1}$

A partir de allí, la novela instaura a la ciudad de La Paz como el punto neurálgico de un tejido donde el entrecruce contradictorio, conflictivo e incompatible de dos culturas, lógicas y cosmovisiones (en

\footnotetext{
${ }^{1}$ En esta entrada, conocida también por su importancia como "La fiesta Mayor de los Andes", participan miles de bailarines agrupados en diferentes fraternidades o comparsas de acuerdo a las danzas que ejecutan: morenada, diablada, llamerada, tinku, caporales, auki-aukis etcétera; entre ellas, la de los "wakawakas". En ésta, las mujeres llevan un cantarito de leche en la mano y visten sobrepuestas varias polleras de diferentes colores que se exponen en las vueltas que realizan al bailar. La novela dice que las de Sara son doce.
} 


\section{REVISTA DE ESTUDIOS BOLIVIANOS}

este caso, la occidental y la indígena aymara-quechua, o genéricamente andina) devienen más sensibles. Y desde donde la vivencia del espacio urbano constituye la posibilidad de los sujetos de internalizarse en el entre-lugar (en principio imposible e inverosímil) de convivencia de esas percepciones, puntos de vista y perspectivas. Lugar tensional y extravagante de contacto que, sin embargo, fue activado ya intensamente en las crónicas indígenas coloniales, como lo subraya Frank Salomón: "Las cuatro (crónicas indígenas) tratan de crear una narrativa diacrónica de la era de la conquista que sea totalmente inteligible para los contemporáneos españoles y, al mismo tiempo, hecha con base en y fiel a materiales andinos ajenos a la diacronía europea [... $]^{\prime 2}$ (Salomon 12).

Recogiendo de principio esta marca de incongruencia, la novela entrecruza sus hilos siguiendo la compleja figura de la paradoja que invoca el misterio que se enciende en el entrecruzarse contradictorio y demoledor de sentidos incompatibles y contrapuestos, a partir del cual suele producirse una inversión sorprendente del sentido que se construye a contrapelo de la lógica común. Mediante su intervención una cosa puede pasar a ser o significar otra; $y$, en ocasiones, llega a constituir espacios marcadamente indeterminados (sajra, en términos de la novela), como la víspera de la Entrada del Gran Poder:

\section{César se confesaba como un fanático de la víspera del Gran Poder, es como si todo fuera a cambiar mañana de manera radical, como si el mundo esperara la llegada de una instancia nueva, tan importante como el día o la noche, decía cada vez que se emocionaba de borracho (9- 10).}

Y precisamente por esta indeterminación la novela se abre permanentemente al desciframiento múltiple, la ambivalencia y la ambigüedad.

\footnotetext{
2 "Chronicles of the impossible: Notes on three Peruvian indigenous historians". En From Oral to Written Expression: Native Andean Chronicles of the Early Colonial Period. Rolena Adorno, ed. Syracuse: Maxwell School of Citizenship and Public Affairs, Syracuse University, 1982: 9-39.
} 


\section{REVISTA DE ESTUDIOS BOLIVIANOS}

Por otro lado, parece tentador pensar la fiesta dentro de la obra de Piñeiro en los términos en los que el carnaval medieval es leído por Mijail Bajtín: un campo fértil para contradicciones, rebajamientos profanadores, ambigüedades, constantes metamorfosis y la relativización de verdades absolutas. Empero también se van entrometiendo diferencias, disparidades y divergencias que se entraman desde la particularidad de lo andino, poniendo en crisis varios de los espacios propios del carnaval occidental. Por ejemplo, si éste marcaba el énfasis en la trasgresión; en la fiesta de Piñeiro se lo pone en la apertura hacia la esperanza y la posibilidad. Si bien la real instauración de la fiesta, el despertar de Sara Chura, supone también una inversión del mundo - un Pachakuti en términos andinos - éste a más de apuntar al humor, tiende a la restauración de un otro orden cultural y social donde el mundo originario no quede discriminado o anulado bajo una lógica colonial. Si bien se habla de metamorfosis en ambos lados, la noción supone, desde la aproximación andina, algo muy distinto al concepto ovidiano.

Y es justamente desde el énfasis que pone la novela boliviana en la piel (aunque cargada también de significación plurivalente y hasta equívoca a diferencia de la máscara carnavalesca) donde acaso se forja y anuda el pacto simbólico con el espacio urbano andino, cuyas convenciones y contradicciones acaban por marcarse como la piel oscura, misteriosa y secreta en principio de Sara, de la fiesta del Gran Poder, de la ciudad de Paz, de Bolivia y de sus habitantes. En Cuando Sara Chura despierte, los personajes son habitantes de nuestra actual ciudad "postmoderna" y parcialmente occidentalizada (digamos); sin embargo, a todos los atraviesa una fuerza de mutación y pasan no sólo de unos trabajos a otros, sino a diferentes seres o "presencias": alacranes, escarabajos, alkamaris, etcétera; asimismo se generan desdoblamientos del mismo ser produciéndose múltiples versiones de variada complejidad.

Por su parte, la ciudad también es percibida como susceptible de vestir varias pieles:

\section{[...] el postizo intuía que esta ciudad tenía un idioma} secreto, una llave para acceder a los murmullos, a los lugares escondidos y al fondo de los precipicios. Era el idioma que hacía visible lo invisible y revelaba la ciudad ancestral que duerme en las profundidades de La Paz (166). 


\section{REVISTA DE ESTUDIOS BOLIVIANOS}

Desde la cita se puede advertir que el develamiento tanto del idioma secreto como de la "ciudad ancestral" y sus otras pieles rumbean el sistema de valoración y deseo que persigue la escritura novelesca. Subrayemos, pues, que a diferencia del disfraz o la máscara, la piel es algo arraigado y supone no un estar sino un ser distinto. Y si el disfrazado y/o enmascarado "sería un intérprete que revela sus otras entidades" (8) en el espacio delimitado del carnaval, las otras pieles de la ciudad y por extensión del país y sus habitantes, cohabitan permanentemente en el mundo, aunque no siempre de manera visible o perceptible.

Con todo y paradójicamente, las pieles no suponen, ni mucho menos, la posibilidad de demarcación de una identidad. Por el contrario, los personajes de la novela se debaten permanentemente en la incertidumbre sobre ella. Así, cuando Don Falsoafán le pide a César Amato que le diga quién es, la contra pregunta del último, con un tono evidentemente burlesco: "¿Acaso usted me puede decir exactamente quién es?", pone al descubierto la fatuidad de la misma (dado que su significación se escapa a quien la formula) y el fracaso del inventor que habría dedicado, caricaturescamente y sin ningún éxito, uno de sus más importantes proyectos "a determinar cómo responder esa pregunta" (34). Conjuntamente, el trasmigrar de piel en piel, presenta a los sujetos en "constante transfiguración" y circulando continuamente por los bordes del torbellino de la indeterminación de sentido que anima todas las cosas en este mundo.

En contraste, acaso paradójico también, el último aspecto de este señalamiento parece abrir puertas a la lectura crítica para poner en escena la actualización de una gramática y campo de significación que, en contraposición, opera con estricta rigurosidad desde la epistemología andina en la novela de Piñeiro. Es el caso de la permanente recurrencia al número cinco, que ligado inconsútilmente con los saberes y vivencias que surgen de la experiencia de vivir la ciudad y concomitantemente con la cosmovisión y cultura andinas más ancestrales, se entreteje a distintos niveles y con distintos puntos y hebras. Focalicemos la más exterior de ellas: la novela se inicia en la página cinco, está dividida en cinco capítulos, los dos primeros y los dos últimos a su vez, en otros cinco subcapítulos. Ya desde aquí, el lector atento se ve retado a pensar los principios constructivos a que responde esa reiteración y descubrirá - con cierto asombro - que la novela misma ha pasado furtivamente y como por un hábil proceso de prestidigitación (acaso corroborando la presentación del escritor Piñeiro en la solapa, como paxpaku iniciado en 


\section{REVISTA DE ESTUDIOS BOLIVIANOS}

"las artes ilusionistas de la ciudad"), de la tradicional secuencia narrativa novelesca, a una horma totalmente distinta. Esta se modela siguiendo en principio la pauta del tejido andino y desde allí, formas complejas de inscripción de la estructura espacio temporal del Tawantinsuyo: la cuatripartición en torno a un eje central lleva a la quintipartición.

Efectivamente, dividida en cinco capítulos, la obra instituye al tercero ("El bolero triunfal de Sara") en núcleo articulador de los cuatro que lo circundan. Además, empiela el principio constructivo al cual responde, marcando su diferencia en relación a los otros: no presenta división alguna, constituye una interrupción al camino más o menos secuencial de la historia novelesca que se había ido entretejiendo ${ }^{3} y$ supone un torcimiento de la prosa a favor del poema-bolero que se sumerge en la mera posibilidad con visos de futuro condicional del "cuando Sara Chura despierte", instituido como el leit-motif semántico y rítmico reiterado a lo largo de todo este capítulo.

Es, pues, la matriz simbólica del Tawantinsuyo (orden no mencionado nunca en la obra) lo que Piñeiro activa, haciéndola funcionar como eje organizador de toda la construcción del sentido de su novela que el lector conocedor o informado podría, quizás, encontrar ya prefigurada en el índice del libro. Esta matriz, además, pone en práctica la capacidad fundamental del cronista Guamán Poma para intervenir y subvertir la cartografía del poder colonial. ${ }^{4}$ De manera parecida, se pueden ir revelando una serie de otros códigos, relaciones intertextuales, configuraciones simbólicas y axiológicas andinas - a primera vista inauditas e invisibles - que organizan y pautan esta novela.

Empero y a contrapelo de la fuerte apoyatura de la obra en lo andino, ésta tiende también una trama con hilos de distinta procedencia, de variadas extensiones e intensidades, colores y gamas que entretejen

\footnotetext{
${ }^{3}$ La historia de base que se cuenta es simple: César Amato ha decidido vestir la piel de detective. En esa condición, recibe una llamada de Sara Chura para encargarle la misión de buscar (hacer aparecer) al Cadáver que respira, pues para que Sara pueda despertar y actualizarse en La fiesta mayor de los Andes, es imprescindible que la otra criatura "desaparezca de este mundo" (27). A partir de ahí, el hilo argumental hace el seguimiento a los pasos de Amato en vista a cumplir el encargo de Sara.

${ }^{4}$ Recuérdese el "Mapamundi" y el "Pontifical Mundo" que se trazan bajo los principios ordenadores del Tawantinsuyo, donde sugestivamente las "Indias del Piru" se presentan en lo alto de España y Castilla en "lo abajo" de las Indias.
} 


\section{REVISTA DE ESTUDIOS BOLIVIANOS}

otros textos literarios (en general no andinos) a la urdimbre novelesca: el mito de Narciso; "la selva oscura" de la Divina Comedia; el Quijote (uno de los personajes, Don Falsoafán, promete a su secretario, el Puntocom, hacerlo jilakata de Warisata, a la manera en que Don Quijote hace a Sancho gobernador de Barataria), y así sucesivamente. Intentemos acercarnos a algunas particularidades del entretejido intertextual mencionado.

Como en la Divina Comedia, lo que Cuando Sara Chura despierte entrama es la urdimbre de una iniciación. ${ }^{5}$ En la obra del poeta italiano, Virgilio - enviado para tal efecto por Beatriz - guía a Dante a través del infierno. En la novela, el Tano (significativamente abreviación de italiano) conduce a César Amato a través de un edificio donde se ubica el boliche "La selva oscura". En el tercer piso espera Sara, quien también ha encomendado esa tarea. En el trayecto, César va reconociendo a algunas personas con las que se entrecruzan y la mención a las gradas que ve desde el primer piso y que ascienden al segundo y tercero, parecen dar la sensación de los círculos arquitectónicos de los trazos del "Infierno" de Dante. Por otro lado, Cuando Sara Chura despierte opera de manera muy semejante a la Divina Comedia cuando pone lo terrible al lado de lo ridículo y enlaza la vida real con la sobrenatural, Asimismo, el lenguaje empleado en la novela es el castellano andino popular propio de La Paz, de manera análoga al que utiliza Dante en la escritura de su obra. Dice Dante: "he empleado en ella [en su obra] el lenguaje vulgar en que se comunican sus ideas hasta las mujeres de ínfima clase" (Canto Primero, nota 1$).{ }^{6}$ De ésta y otras maneras se podría ir estableciendo diferentes puntos de contacto entre la obra del poeta italiano y la obra boliviana sin que en ésta, sin embargo, se nombre o refiera a Dante ni a su Comedia en ningún momento, a más del título del boliche ya aludido.

Quizás lo más adecuado sería pensar que esta breve novela logra entrecruzarse galanamente con Dante y su Comedia sobre todo por la medida de su ambición: la tentativa de construir una poderosa figuración de la ciudad de La Paz en día de fiesta, donde el hilo del entrecruce

\footnotetext{
${ }^{5}$ La novela presenta las prácticas de la multicultural y contradictoria configuración de la ciudad de La Paz y por extensión de Bolivia y sus habitantes. Entre una de esas prácticas está la constitución y la relación con lo sagrado.

${ }^{6}$ Dante Alighieri. 1970 [1304-1321]. La Divina Comedia. Barcelona: Iberia, 1970.
} 


\section{REVISTA DE ESTUDIOS BOLIVIANOS}

imposible de las culturas y las lógicas occidentalizadas y originarias de nuestra América se activa nueva e intensamente y donde queda expresada la fuerte y dinámica presencia de lo andino en la cultura, las estructuras simbólicas, el imaginario y las vivencias, usos y costumbres de sus habitantes. Y re-articulada una vez más, de manera enriquecida e innovadora, la esperanza del advenimiento de un nuevo orden sociocultural que los indígenas prefiguraron ya en el mito del Inkarrí después de la muerte del Inca Atahuallpa.

Rosario Rodríguez-Márquez

Universidad Mayor de San Andrés

\section{(cc) BY-NC-ND}

This work is licensed under a Creative Commons Attribution-

Noncommercial-No Derivative Works 3.0 United States License. 